\title{
(C) OPEN ACCESS \\ What US hospitals are currently doing to prevent common device- associated infections: results from a national survey
}

\author{
Sanjay Saint, ${ }^{\oplus, 2}$ Michael Todd Greene, ${ }^{1,2}$ Karen E Fowler, ${ }^{\circledR}{ }^{1}$ David Ratz, ${ }^{1}$ \\ Payal K Patel, ${ }^{2,3}$ Jennifer Meddings, ${ }^{1,2,4}$ Sarah L Krein $^{\oplus 1,2}$
}

- Additional material is published online only. To view please visit the journal online (http://dx.doi.org/10.1136/ bmjqs-2018-009111).

${ }^{1}$ Center for Clinical Management Research, VA Ann Arbor Healthcare System, Ann Arbor, MI, USA

${ }^{2}$ Department of Internal Medicine, University of Michigan Medical School, Ann Arbor, MI, USA

${ }^{3}$ Division of Infectious Diseases, VA Ann Arbor Healthcare System, Ann Arbor, MI, USA ${ }^{4}$ Department of Pediatrics and Communicable Diseases, University of Michigan Medical School, Ann Arbor, MI, USA

\section{Correspondence to}

Dr Sanjay Saint, University of Michigan, Ann Arbor, Ml 48109, USA; saint@med.umich.edu

Received 19 November 2018 Revised 18 March 2019 Accepted 27 March 2019 Published Online First 23 April 2019

\begin{abstract}
Background Despite focused initiatives to reduce device-associated infection among hospitalised patients, the practices US hospitals are currently using are unknown. We thus used a national survey to ascertain the use of several established and novel practices to prevent device-associated infections.

Methods We mailed surveys to infection preventionists in a random sample of nearly 900 US acute care hospitals in 2017. Our survey asked about the use of practices to prevent three common device-associated infections: catheter-associated urinary tract infection (CAUTI), central line-associated bloodstream infection (CLABSI) and ventilator-associated pneumonia (VAP). Using sample weights, we estimated the percentage of hospitals reporting regular use of each practice. We also conducted multivariable regression to determine associations between selected hospital characteristics (eg, perceived support from leadership) and use of CAUTI, CLABSI and VAP prevention practices.

Results The response rate was $59 \%$. Several practices are reportedly used in over $90 \%$ of US hospitals: aseptic technique during indwelling urethral catheter insertion and maintenance (to prevent CAUTI); maximum sterile barrier precautions during central catheter insertion and alcohol-containing chlorhexidine gluconate for insertion site antisepsis (to prevent CLABSI); and semirecumbent positioning of the patient (to prevent VAP). Antimicrobial devices are used in the minority of hospitals for these three device-associated infections.

Conclusions We provide an updated snapshot of the practices US hospitals are currently using to prevent device-associated infections. Compared with previous studies using a similar design and questions, we found that the use of recommended practices increased in US hospitals, especially for CAUTI prevention.
\end{abstract}

\section{INTRODUCTION}

Hospitals in the United States (US) continue to focus on enhancing the safety of their patients with special emphasis in preventing healthcare-associated infection (HAI). Several initiatives over the last decade have encouraged HAI prevention efforts. In 2008, for example, hospital payment policies from the Centers for Medicare and Medicaid Services (CMS) ended certain HAIs from yielding additional hospital payment as comorbidities, including catheter-associated urinary tract infection (CAUTI) and central line-associated bloodstream infection (CLABSI). ${ }^{1}$ That same year, a federal steering committee was established that eventually developed a National Action Plan to Prevent HAI. ${ }^{2}$ In October 2016, the Department of Health and Human Services announced new national targets for the National Action Plan to Prevent HAI, with goals of reducing CAUTI by $25 \%$ and CLABSI by $50 \%$ by $2020 .{ }^{3}$ HAI was also identified as a Healthy People 2020 objective $^{45}$ and the Partnership for Patients-a public-private partnershipincludes a clear focus on HAI prevention activities. ${ }^{6}$ Public reporting of infection rates was mandated by some states beginning in $2002,{ }^{7}$ and starting in 2015 , both the Hospital Acquired Conditions Reduction Program ${ }^{8}$ as well as the Hospital Value-Based Purchasing Program ${ }^{9}$ use the following HAI measures to compare and penalise hospital performance by reducing Medicare payment: CAUTI, CLABSI, Clostridioides difficile infection, methicillin-resistant Staphylococcus aureus and surgical site infection after colon surgery and abdominal hysterectomy. ${ }^{10}$

Not surprisingly given this national attention, several large-scale HAI implementation initiatives have been conducted, including collaboratives concentrating on device-related infections. ${ }^{11-17}$ Such collaborative efforts usually emphasise the importance of implementing certain evidence-based practices to prevent HAIs. Nonetheless, how these efforts, along with other recent publications focusing 
on novel practices and approaches to preventing device-related infection, have affected practice use is unknown. ${ }^{18-20}$ We thus sought to evaluate the use of current established and novel practices to prevent device-associated infections by US acute care hospitals.

\section{METHODS}

\section{Study design and data collection}

This cross-sectional survey is part of an ongoing project in which, every 4 years, we ask infection preventionists across the US what practices their hospitals are using to prevent common HAIs. ${ }^{21}{ }^{22}$ For the first wave in 2005, a national random sample was selected by identifying all non-federal, general medical and surgical hospitals with an intensive care unit and at least 50 hospital beds using the 2003 American Hospital Association (AHA) Database. As data from the 2003 AHA database may no longer reflect the current distribution of US hospitals, for the fourth (2017) wave, we resampled based on AHA fiscal year 2013 data. Specifically, for feasibility, we randomly sampled 900 general medical and surgical hospitals with an intensive care unit. However, unlike prior years, hospitals of all bed sizes were included. Three of the sampled facilities were later excluded since they had either closed or were no longer an acute care facility, resulting in an initial sample of 897 hospitals.

The study surveys were mailed to the hospital infection preventionist in May 2017. At hospitals that employ more than one infection preventionist, we asked that the lead infection preventionist serve as the primary respondent, although we encouraged consulting with others as needed to complete the questionnaire. The survey process followed a modified Dillman approach, ${ }^{23}$ which included an initial mailed invitational letter and survey, a reminder postcard after approximately 2 weeks and additional survey mailings at 1 month, 2 months and 5 months to those who had not yet responded. The final reminders to non-respondents were sent in October 2017. This study received an exemption from the local institutional review board.

\section{Study measures}

The main outcome for our analysis is a binary variable $(0 / 1)$ indicating regular use of evidence-based recommendations to prevent CAUTI, CLABSI and ventilator-associated pneumonia (VAP). The survey included questions about different practices related to each type of device-associated infection based on various guidelines. ${ }^{24-28}$ We asked about practices that are generally recommended, some that are considered special approaches when infection rates are not controlled and some that are not recommended for routine use. ${ }^{26-28}$ Respondents were asked to rate the frequency of use for each practice on a scale from 1 to 5 ( 1 being 'never use' and 5 being 'always use'). Regular use of a practice was defined as receiving a rating of 4 or 5 , whereas values of 1-3 were considered reflective of lack of use of a practice on a regular basis. Information about general hospital characteristics, including the number of intensive care unit beds, affiliation with a medical school, presence of hospitalists and characteristics of the infection control and prevention programme was also collected. The survey included questions about the presence of monitoring and other hospital practices related to each infection, such as routine urine testing at hospital admission. The perception of how important it is to hospital leadership to prevent urinary tract infections, central venous catheter-related infections or VAP was assessed on a scale of 1-4 (1 being 'minimally important' and 4 being 'extremely important'). Similar to our outcome variables, we constructed a binary variable with strong importance to hospital leadership to prevent urinary tract infections, central venous catheter-related infections and VAP, defined as responses of 3 (very important) or 4 (extremely impor$\operatorname{tant}$ ), coded as 1 and 0 otherwise.

\section{Statistical analysis}

Sampling weights based on the inverse probability of selection and responses in each bed size stratum $(<50$, $50-250$ and $>250$ ) were used to create nationally representative estimates for HAI practices and hospital characteristics. Bed size was derived by linking survey-respondent hospitals to the AHA 2013 annual survey. Descriptive statistics are reported as weighted proportions (and 95\% CIs) for categorical variables and weighted means (and 95\% CI) for continuous variables.

We conducted multivariable logistic regression to determine associations between various hospital and infection control programme characteristics and regular use of specific CAUTI, CLABSI and VAP prevention practices. All models were adjusted for total number of adult acute care or intensive care unit beds, medical school affiliation, involvement in a HAI collaborative, overall support for infection control programme from hospital leadership, presence of a hospital epidemiologist and whether the lead infection preventionist is certified in infection control. Other domain-specific independent variables (eg, perception of how important it is to hospital leadership to prevent CAUTI, CLABSI or VAP, and various CAUTI, CLABSI and VAP surveillance measures) were included within multivariable models if significant in bivariable analyses. The sample size may vary due to missing data.

\section{Subset comparison analysis}

As indicated above, prior waves of the survey targeted hospitals with at least 50 beds. The 2017 survey was expanded to include smaller/critical access hospitals. Additionally, we selected a new random sample in 2017 (ie, did not explicitly resample respondents from prior survey waves). As such, we are unable to look at longitudinal changes among a specific subset of hospitals responding across multiple surveys. Still, observing changes in infection prevention practices over time are 
important, and therefore we have done the following for the analyses comparing 2013 with 2017 responses. First, we applied sample weights to the 2013 and 2017 survey data for comparability between these two survey waves. Second, we dropped smaller/critical access hospitals from the 2017 responses. Third, we conducted weighted, cross-sectional comparisons of the various infection prevention practices between the 2013 and the 2017 survey subset.

A $\mathrm{p}$ value $<0.05$ was considered significant. SAS V.9.4 was used for all analyses.

\section{RESULTS}

The overall survey response rate was 59\% (530/897). Two surveys were returned with the study identification code removed. As we were unable to link these hospitals to the AHA survey to calculate sampling weights they were dropped from this analysis, leaving a total of 528 hospitals. Data from the 2013 AHA Annual Survey were used to compare responders to non-responders on the following characteristics: urban versus rural; profit versus non-profit; teaching versus non-teaching; and total number of hospital beds. A statistically significant higher percentage of non-responding hospitals compared with responding hospitals were in urban regions $(84.8 \%$ versus $78.2 \%, \mathrm{p}=0.014)$ and non-responders had a larger average number of hospital beds ( 237.8 versus $202.6, p=0.012$ ). There were no statistically significant differences in profit and teaching status.

Selected hospital characteristics from the survey are shown in table 1 . The average reported bed size of responding hospitals was 193 beds; $76 \%$ of the beds were reported to be in private rooms. Over 26\% of hospitals were affiliated with a medical school. Although nearly $80 \%$ of hospitals were involved in collaborative efforts to reduce HAI, only $53 \%$ of

\begin{tabular}{|c|c|}
\hline Characteristic & Mean or $\%(95 \% \mathrm{Cl})$ \\
\hline $\begin{array}{l}\text { Total number of adult acute care beds } \\
\text { (including intensive care unit beds) }\end{array}$ & 192.91 (176.42 to 209.40$)$ \\
\hline $\begin{array}{l}\text { Total number of adult intensive care unit } \\
\text { beds }\end{array}$ & 20.98 (18.70 to 23.26$)$ \\
\hline \multicolumn{2}{|l|}{$\begin{array}{l}\text { Approximately what percentage of your } \\
\text { rooms are }\end{array}$} \\
\hline Private (one patient) & 75.66 (72.86 to 78.45$)$ \\
\hline Semiprivate (two or more patients) & 24.58 (21.76 to 27.39$)$ \\
\hline Hospital affiliated with a medical school & $26.23(22.35$ to 30.10$)$ \\
\hline $\begin{array}{l}\text { Involved in collaborative effort to reduce } \\
\text { healthcare-associated infections }\end{array}$ & 79.08 (75.54 to 82.62 ) \\
\hline $\begin{array}{l}\text { Very good/excellent overall support of } \\
\text { infection prevention and control programme } \\
\text { from hospital leadership }\end{array}$ & 53.13 (48.84 to 57.41$)$ \\
\hline Presence of a hospital epidemiologist & 41.31 (37.05 to 45.56$)$ \\
\hline $\begin{array}{l}\text { Lead infection preventionist certified in } \\
\text { infection prevention and control }\end{array}$ & 61.98 (57.83 to 66.12$)$ \\
\hline
\end{tabular}

hospitals reported receiving strong to very strong support for the infection control programme from hospital leadership. Over $41 \%$ of hospitals reported that they had a hospital epidemiologist; $62 \%$ had a lead infection preventionist certified in infection control.

The percentage of hospitals regularly using the various practices to prevent CAUTI, CLABSI and VAP is illustrated in figure 1.

\section{Practices to prevent CAUTI}

Regular use of portable bladder ultrasound scanners was reported in $73.2 \%$ (95\% CI $69.3 \%$ to $77.0 \%$ ) of hospitals. The percentage of hospitals using urinary catheter reminders or stop-orders was 75.3\% (95\% CI $71.5 \%$ to $79.0 \%$ ). A total of $26.8 \%$ (95\% CI $22.9 \%$ to $30.7 \%$ ) were regularly using silver alloy Foley catheters; the same percentage also reported routinely using condom catheters in men. Aseptic technique during catheter insertion and maintenance was regularly used in $90.0 \%$ (95\% CI $87.3 \%$ to $92.6 \%$ ) of hospitals. The percentage of hospitals that reported having an established surveillance system for monitoring urinary tract infection rates facility wide was $93.2 \%$.

\section{Practices to prevent CLABSI}

Two key recommended practices-maximum sterile barrier precautions during central line insertion and chlorhexidine gluconate for insertion site antisepsiswere reportedly being used regularly by nearly $100 \%$ of responding hospitals. The percentage of hospitals using antimicrobial-coated catheters was 40.7\% (95\% CI $36.4 \%$ to $45.0 \%$ ), while use of an antimicrobial dressing with chlorhexidine was $89.1 \%$ (95\% CI $86.4 \%$ to $91.8 \%)$. The percentage of hospitals with an established surveillance system for monitoring CLABSI rates facility wide was $92.8 \%$.

\section{Practices to prevent VAP}

The most commonly used practice to prevent VAP was semirecumbent positioning of the patient $(98.2 \%$, 95\% CI $97.0 \%$ to $99.4 \%)$. A total of $83.6 \%$ (95\% CI $80.3 \%$ to $86.8 \%$ ) of hospitals used antimicrobial mouth rinse, $57.6 \%$ (95\% CI $53.2 \%$ to $62.1 \%$ ) used subglottic secretion drainage and $24.4 \%$ (95\% CI $20.5 \%$ to $28.3 \%$ ) used topical and/or systemic antibiotics for selective digestive tract decontamination. Finally, the percentage of hospitals with an established surveillance system for monitoring VAP rates facility wide or unit specific was $93.6 \%$.

\section{Multivariable regression models}

Statistically significant associations from logistic multivariable models within the CAUTI, CLABSI and VAP prevention domains are shown in table 2 .

For CAUTI, perceived strong importance to hospital leadership to prevent urinary tract infections was significantly associated with increased odds of 
A

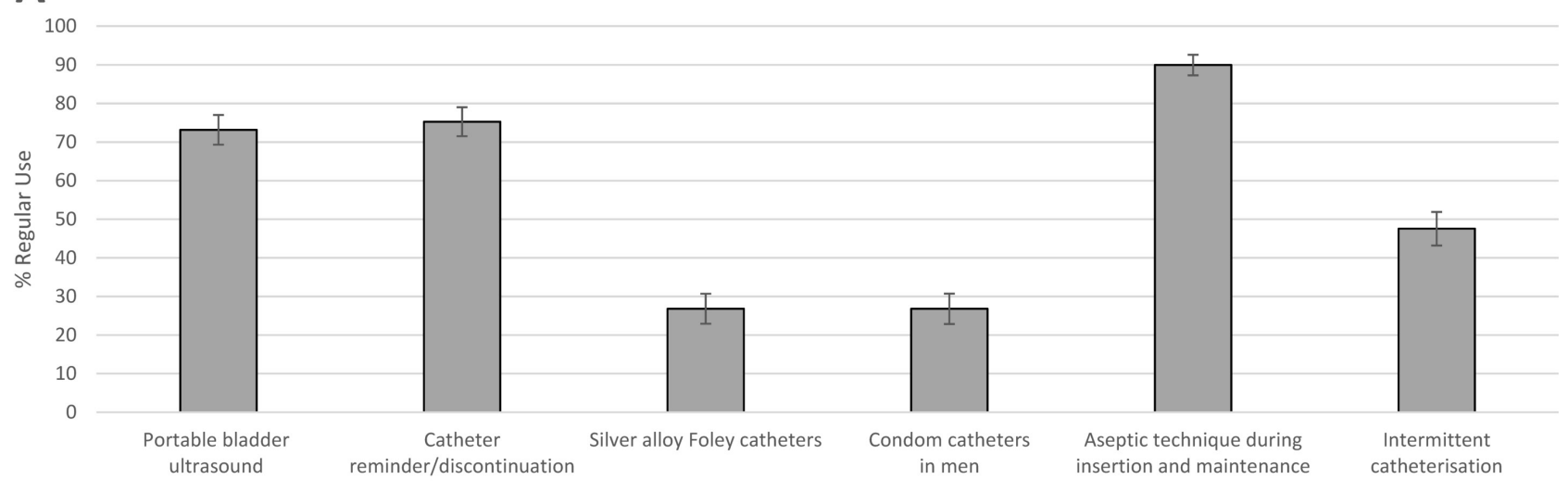

B

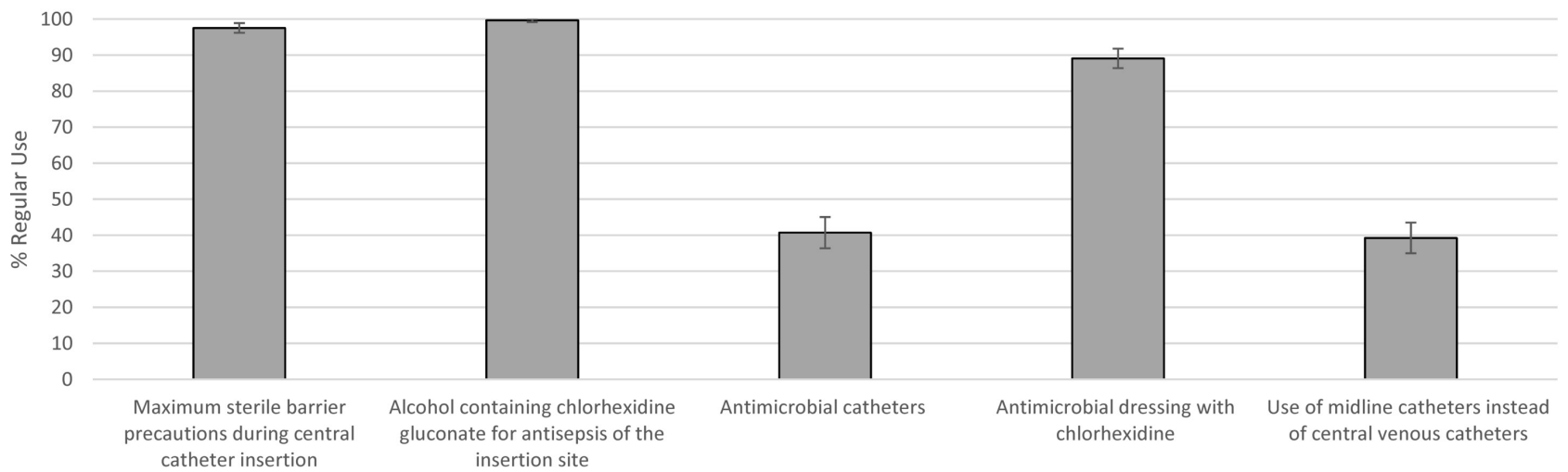

C

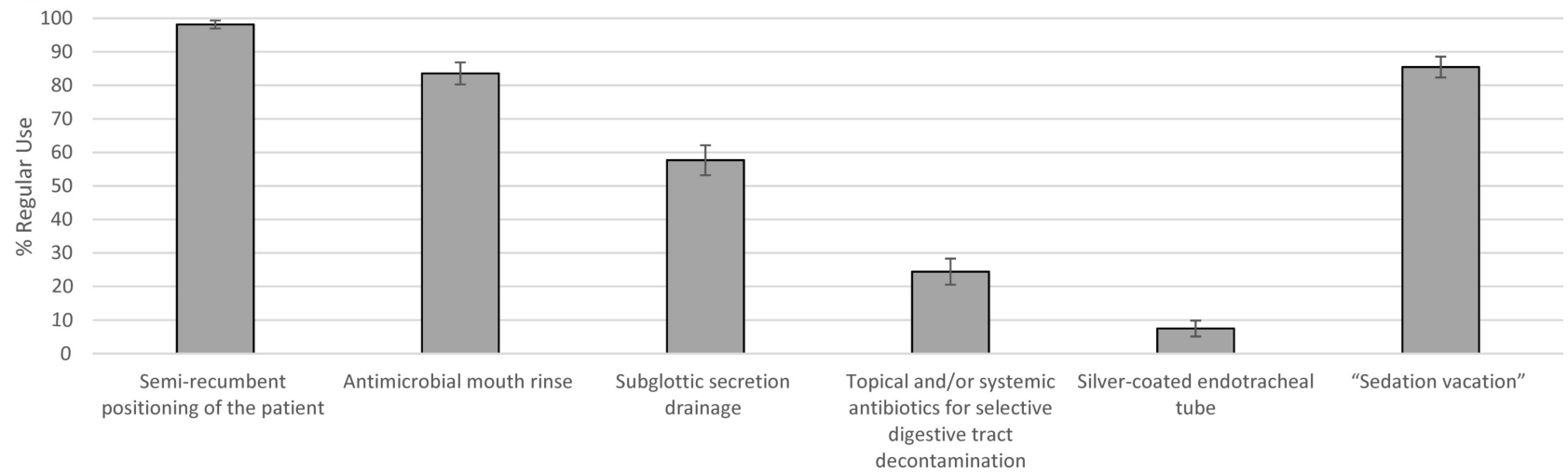

Figure 1 Regular use of practices to prevent CAUTI, CLABSI and VAP. (A) CAUTI prevention practices. (B) CLABSI prevention practices. (C) VAP prevention practices. CAUTI, catheter-associated urinary tract infection; CLABSI, central line-associated bloodstream infection; VAP, ventilator-associated pneumonia.

regularly using the following recommended practices: portable bladder ultrasound scanning $(\mathrm{OR}=2.04$; 95\% CI 1.17 to 3.54$)$; urinary catheter reminder/ nurse-initiated catheter discontinuation $(\mathrm{OR}=2.64$; $95 \%$ CI 1.43 to 4.88 ); and routinely using condom catheters in men $(\mathrm{OR}=2.93 ; 95 \% \mathrm{CI} 1.30$ to 6.60$)$. Hospitals that reported routinely monitoring the duration and/or discontinuation of urinary catheters had increased odds of regularly using catheter reminders or stop-orders and/or nurse-initiated discontinuation $(\mathrm{OR}=3.35 ; 95 \% \mathrm{CI} 1.61$ to 6.96$)$; aseptic technique during catheter insertion and maintenance $(\mathrm{OR}=2.85$; $95 \%$ CI 1.28 to 6.36 ) and intermittent catheterisation $(\mathrm{OR}=2.32 ; 95 \%$ CI 1.23 to 4.38$)$.

For CLABSI, hospitals involved in an HAI collaborative $(\mathrm{OR}=3.16$; 95\% CI 1.06 to 9.46) and those with perceived strong importance to hospital leadership to prevent central venous catheter infections $(\mathrm{OR}=4.24$; $95 \%$ CI 1.28 to 14.05 ) had increased odds of regularly using maximum sterile barrier precautions. Having strong overall support for the infection control programme from hospital leadership was associated 
Table 2 Significant predictors of select CAUTI, CLABSI and VAP prevention practices*

\begin{tabular}{|c|c|c|c|}
\hline Independent variable & Prevention practice & OR $(95 \% \mathrm{Cl})$ & $P$ value \\
\hline \multicolumn{4}{|l|}{ CAUTI† } \\
\hline \multirow{4}{*}{$\begin{array}{l}\text { Important/very important to hospital } \\
\text { leadership to prevent urinary tract } \\
\text { infection }\end{array}$} & Portable bladder ultrasound & 2.04 (1.17 to 3.54$)$ & 0.01 \\
\hline & $\begin{array}{l}\text { Urinary catheter reminder/stop } \\
\text { order and/or nurse-initiated catheter } \\
\text { discontinuation }\end{array}$ & 2.64 (1.43 to 4.88$)$ & 0.002 \\
\hline & Silver alloy catheters & 2.07 (1.05 to 4.09$)$ & 0.04 \\
\hline & Condom catheters in men & $2.93(1.30$ to 6.60$)$ & 0.01 \\
\hline Presence of hospital epidemiologist & $\begin{array}{l}\text { Urinary catheter reminder/stop } \\
\text { order and/or nurse-initiated catheter } \\
\text { discontinuation }\end{array}$ & $1.95(1.12$ to 3.39$)$ & 0.02 \\
\hline \multirow[t]{3}{*}{$\begin{array}{l}\text { Routine monitoring of duration and/ } \\
\text { discontinuation of urinary catheters }\end{array}$} & $\begin{array}{l}\text { Urinary catheter reminder/stop } \\
\text { order and/or nurse-initiated catheter } \\
\text { discontinuation }\end{array}$ & 3.35 (1.61 to 6.96$)$ & 0.001 \\
\hline & $\begin{array}{l}\text { Aseptic technique during catheter } \\
\text { insertion and maintenance }\end{array}$ & 2.85 (1.28 to 6.36$)$ & 0.01 \\
\hline & Intermittent catheterisation & $2.32(1.23$ to 4.38$)$ & 0.01 \\
\hline $\begin{array}{l}\text { Lead infection preventionist certified } \\
\text { in infection control }\end{array}$ & Condom catheters in men & $2.00(1.14$ to 3.49$)$ & 0.02 \\
\hline $\begin{array}{l}\text { Very good/excellent overall support } \\
\text { of infection prevention and control } \\
\text { programme from hospital leadership }\end{array}$ & $\begin{array}{l}\text { Aseptic technique during catheter } \\
\text { insertion and maintenance }\end{array}$ & 2.25 (1.16 to 4.36$)$ & 0.02 \\
\hline $\begin{array}{l}\text { Routine urine test to screen for } \\
\text { urinary tract infection at hospital } \\
\text { admission }\end{array}$ & $\begin{array}{l}\text { Aseptic technique during catheter } \\
\text { insertion and maintenance }\end{array}$ & 5.05 (1.53 to 16.6$)$ & 0.01 \\
\hline
\end{tabular}

\section{CLABSI $\ddagger$}

Involved in collaborative effort to reduce healthcare-associated infections

\begin{tabular}{|c|c|c|c|}
\hline $\begin{array}{l}\text { Important/very important to hospital } \\
\text { leadership to prevent central } \\
\text { catheter infection }\end{array}$ & $\begin{array}{l}\text { Maximum sterile barrier precautions } \\
\text { during central catheter insertion }\end{array}$ & 4.24 (1.28 to 14.05$)$ & 0.02 \\
\hline $\begin{array}{l}\text { Lead infection preventionist certified } \\
\text { in infection control }\end{array}$ & Antimicrobial catheters & 0.50 (0.32 to 0.76$)$ & 0.001 \\
\hline $\begin{array}{l}\text { Hospital affiliated with medical } \\
\text { school }\end{array}$ & $\begin{array}{l}\text { Antimicrobial dressing with } \\
\text { chlorhexidine }\end{array}$ & 0.38 (0.21 to 0.70$)$ & 0.002 \\
\hline $\begin{array}{l}\text { Very good/excellent overall support } \\
\text { of infection prevention and control } \\
\text { programme from hospital leadership }\end{array}$ & $\begin{array}{l}\text { Antimicrobial dressing with } \\
\text { chlorhexidine }\end{array}$ & 1.79 (1.01 to 3.18$)$ & 0.05 \\
\hline $\begin{array}{l}\text { Daily rounds to assess ongoing } \\
\text { necessity of peripherally inserted } \\
\text { central catheters }\end{array}$ & $\begin{array}{l}\text { Use of midline catheters instead of } \\
\text { central venous catheters }\end{array}$ & $2.19(1.40$ to 3.45$)$ & 0.001 \\
\hline \multicolumn{4}{|l|}{ VAP $\S$} \\
\hline $\begin{array}{l}\text { Involved in collaborative effort } \\
\text { to reduce healthcare-associated } \\
\text { infections }\end{array}$ & Antimicrobial mouth rinse & 2.21 (1.24 to 3.93) & 0.01 \\
\hline \multirow{2}{*}{$\begin{array}{l}\text { Lead infection preventionist certified } \\
\text { in infection control }\end{array}$} & Antimicrobial mouth rinse & $1.95(1.14$ to 3.31$)$ & 0.01 \\
\hline & 'Sedation vacation' & 1.90 (1.09 to 3.31$)$ & 0.03 \\
\hline \multirow{3}{*}{$\begin{array}{l}\text { Important/very important to hospital } \\
\text { leadership to prevent ventilator- } \\
\text { associated pneumonia }\end{array}$} & Antimicrobial mouth rinse & 2.10 (1.17 to 3.75$)$ & 0.01 \\
\hline & Subglottic secretion drainage & 1.73 (1.08 to 2.78$)$ & 0.02 \\
\hline & $\begin{array}{l}\text { Topical and/or systemic antibiotics } \\
\text { for selective digestive tract } \\
\text { decontamination }\end{array}$ & 2.31 (1.27 to 4.20$)$ & 0.01 \\
\hline
\end{tabular}

Continued

Maximum sterile barrier precautions $\quad 3.16(1.06$ to 9.46) $\quad 0.04$ during central catheter insertion

$4.24(1.28$ to 14.05$)$

$0.50(0.32$ to 0.76$)$

$0.38(0.21$ to 0.70$)$

Antimicrobial dressing with $\quad 1.79(1.01$ to 3.18$)$

Use of midline catheters instead of $\quad 2.19(1.40$ to 3.45$) \quad 0.001$ central venous catheters 
Table 2 Continued

\begin{tabular}{|c|c|c|c|}
\hline Independent variable & . & OR $(95 \% \mathrm{CI})$ & value \\
\hline $\begin{array}{l}\text { ry good/excellent overall support } \\
\text { infection prevention and control } \\
\text { ogramme from hospital leadership }\end{array}$ & decontamination & $0.53(0.33$ to 0.85$)$ & \\
\hline ventilated patients & es & 6.52 (1.48 to 28.77$)$ & \\
\hline \multicolumn{4}{|c|}{ 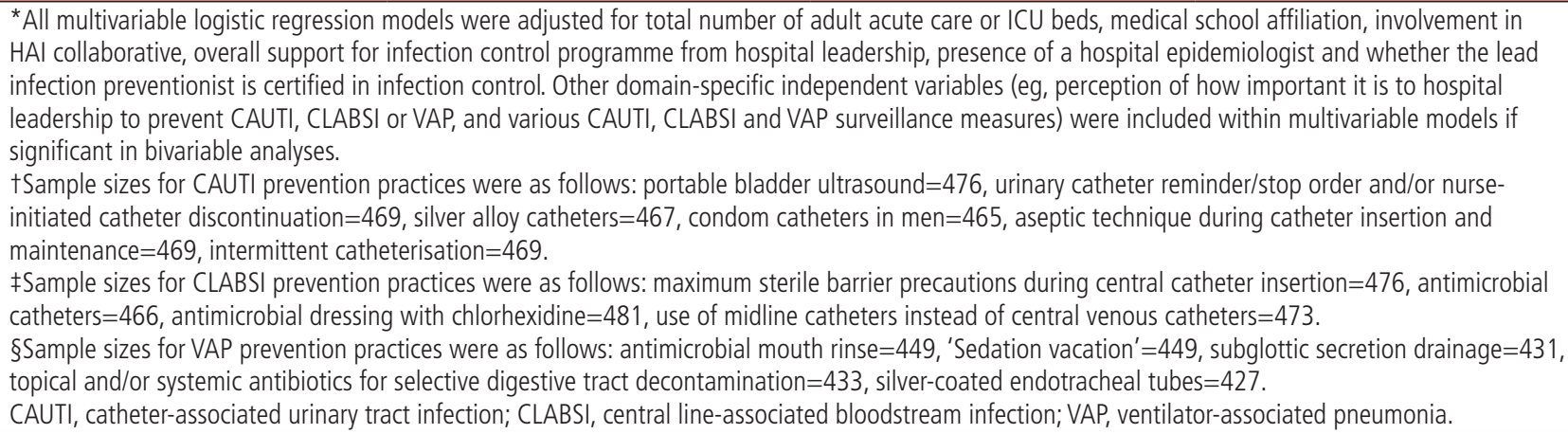 } \\
\hline
\end{tabular}

with increased odds of regularly using antimicrobial dressings with chlorhexidine (OR $=1.79 ; 95 \%$ CI 1.01 to 3.18 ).

For VAP, two variables were also associated with the use of several practices. Hospitals with perceived strong importance to hospital leadership to prevent VAP had increased odds of regularly using antimicrobial mouth rinse (OR: 2.10; 95\% CI 1.17 to 3.75 ), subglottic secretion drainage (OR: 1.73; 95\% CI 1.08 to 2.78 ) and using topical and/or systemic antibiotics for selective digestive tract decontamination (OR: 2.31; 95\% CI 1.27 to 4.20). Hospitals with a lead infection preventionist certified in infection prevention and control had significantly increased odds of regularly using antimicrobial mouth rinse (OR: 1.95; 95\% CI 1.14 to 3.31) and 'sedation vacation' (OR: $1.90 ; 95 \%$ CI 1.09 to 3.31 ).

\section{Cross-sectional comparisons 2013 vs 2017 surveys}

A total of 403 hospitals responded to our 2013 survey. For this comparison, 98 smaller hospitals (bed size less than 50) responding to the 2017 survey were dropped, leaving 430 hospitals included in this analysis. Comparisons of regular use of various practices to prevent CAUTI, CLABSI and VAP between 2013 and 2017 are presented in the online supplementary material. For CAUTI, notable increases were seen in portable bladder ultrasound scanner use from 56.4\% to $74.8 \%(\mathrm{p}<0.001)$, urinary catheter reminders/nurse discontinuation from $62.7 \%$ to $76.9 \%(\mathrm{p}<0.001)$, routine condom catheter use in men from $13.4 \%$ to $29.8 \%(\mathrm{p}<0.001)$ and intermittent catheterisation from $30.8 \%$ to $49.8 \%(p<0.001)$. The percentage of hospitals with an established surveillance system for monitoring urinary tract infection rates increased from $85.1 \%$ to $94.2 \%(p<0.001)$. For CLABSI, we found increases in use of antimicrobial catheters $32.2 \%$ to $41.7 \% \quad(p=0.01)$ and antimicrobial dressing with chlorhexidine $78.2 \%$ to $90.0 \%(p<0.001)$. Although no increases were noted, both maximum sterile barrier precautions and use of chlorhexidine gluconate for insertion site antisepsis were nearly universally used in both survey years. The percentage of hospitals with an established surveillance system for monitoring CLABSI rates also increased modestly from $89.9 \%$ to $93.5 \%$ $(p=0.07)$. For VAP, only use of antimicrobial mouth rinse increased from $79.4 \%$ to $85.6 \%(\mathrm{p}=0.02)$. The percentage of hospitals with an established surveillance system for monitoring VAP rates decreased slightly from $95.7 \%$ to $93.4 \%(p=0.19)$.

\section{DISCUSSION}

We conducted a national survey to ascertain what US hospitals are currently doing to prevent the three most common device-related HAIs. We have three main findings. First, several practices are reportedly used in over $90 \%$ of US hospitals such as aseptic technique during indwelling urethral catheter insertion and maintenance (to prevent CAUTI), maximum sterile barrier precautions during central catheter insertion and alcohol-containing chlorhexidine gluconate for insertion site antisepsis (to prevent CLABSI) and semirecumbent positioning of the patient (to prevent VAP). Second, antimicrobial devices are used in the minority of hospitals regardless of the device-associated infection. Third, the responses to several questions-specifically, perceived importance of preventing the specific infection and certification in infection prevention status by the lead infection preventionist-were associated with the use of several practices across the device-related infection domains investigated.

Our multivariable models uncovered some noteworthy associations between certain hospital characteristics and the use of various HAI preventive practices. The variables that had the highest number of significant associations with practice use were 
perceived importance of preventing the specific infection by hospital leadership and certification in infection prevention status by the lead infection preventionist. Perceived importance of preventing the particular infection makes sense and underscores the salience of obtaining leadership support for the HAI prevention initiative. We also found that being certified in infection prevention made it more likely that the hospital would use condom catheters for men (to prevent CAUTI), alcohol-containing chlorhexidine gluconate for insertion site antisepsis (to prevent CLABSI) and antimicrobial mouth rinse and a 'sedation vacation' (to prevent VAP). Certification was inversely associated with the use of antimicrobial catheters to prevent CLABSI. We hypothesise that certification might lead to better knowledge and mastery of current infection prevention practices, as we have reported before. ${ }^{29}$

We have been conducting national surveys in US hospitals every 4 years since 2005 , which allows us to consider the possible impact of external factors on HAI prevention practices. ${ }^{21}$ For example, this most recent survey provides an updated assessment of HAI prevention practices in use after the introduction of the CMS Hospital Acquired Conditions Reduction Program and the additional focus on HAIs in the Hospital ValueBased Purchasing Program, both of which penalise low-performing hospitals based on HAI quality measures. ${ }^{89}$ Compared with our last survey in 2013, several key changes were observed. The most notable changes involved CAUTI prevention. This included increases in recommended practices ${ }^{26}$ such as using reminders or stop orders for catheter discontinuation and promoting the use of alternatives to indwelling urethral catheters. These recommended practices were all included in a large-scale CAUTI collaborative that reported a 32\% decrease in CAUTI rates among patients on the medical surgical floor. ${ }^{12}$

For CLABSI prevention, more modest changes were noted. Maximum sterile barrier precautions during central catheter insertion and alcohol-containing chlorhexidine gluconate for insertion site antisepsis reached near saturation in US hospitals likely related to both guideline recommendations and the large-scale collaboratives that used bundles in which both were incorporated. ${ }^{132730}$ Two practices-use of antimicrobial catheters and antimicrobial dressing with chlorhexidine-also showed modest increases in use between the 2013 and 2017 surveys. The reasons are unclear but could be related to continued focus on CLABSI prevention as a quality measure, general comfort level with using chlorhexidine-containing products and published guidance in 2014 that recommended using antimicrobial catheters and antimicrobial dressing with chlorhexidine (both rated as high quality evidence) in hospitals with high CLABSI rates despite other interventions. $^{27}$

For VAP, the six practices we queried were reportedly used in essentially the same proportions in 2013 and in 2017 except for an increase in the reported use of antimicrobial mouth rinse. One reason for this increase could be related to the findings from a 2016 Cochrane review that stated: 'We found high quality evidence that chlorhexidine, either as a mouth rinse or a gel, reduces the risk of VAP from $24 \%$ to about $18 \%$. ${ }^{31}$ Also, as with CLABSI, a general acceptance of the preventive utility of chlorhexidine could be a contributing factor.

Even though we employed national sampling and achieved an acceptable response rate for surveys of healthcare workers, several important limitations must be acknowledged. First, we relied entirely on self-report from the lead infection preventionist at each hospital to determine the practices used to prevent HAIs. It is therefore possible that he or she may have understated or overstated the use of various practices. Second, although we surveyed approximately $10 \%$ of all US hospitals and our sampling strategy was intended to obtain a nationally representative sample, participating hospitals may have been different from non-participating hospitals, thereby making the results less generalisable. Third, while our multivariable models identified several factors associated with the use of various HAI preventive practices, the nature of our cross-sectional study prevents us from determining the causal relationship between these factors and the use of a particular practice. Since our goal was not to draw any causal conclusions from these analyses but to identify important potential associations for future research, we did not adjust for multiple comparisons so the potential for a type I error is increased. A rigorous qualitative evaluation in which formal interviews and site visits are conducted would be able to provide detailed data to gain insights into why some hospitals are using a particular practice while others are not; we have conducted and reported such studies previously. ${ }^{32-34}$

Despite these important limitations, we provide an updated view of what practices US hospitals are currently using to prevent common device-related HAIs. Additionally, we identified several factors that are associated with the use of various practices. Finally, compared with previous studies using a similar design and questions, we found that the use of evidence-based and recommended practices has increased in US hospitals especially for CAUTI prevention and remained high for CLABSI prevention. Surveys such as this one-and previous national snapshots-allow policy makers, decision makers and clinicians to modify their approach to HAI prevention with the goal of reducing common, costly and often lethal complications of hospitalisation.

Contributors Concept and design: SS, MTG, KEF and SLK; data acquisition: SS, KEF, JM and SLK. Data analysis: MTG and DR. Data interpretation: all authors; drafting of the manuscript: SS, MTG and KEF; critical revision of the manuscript: all authors; obtained funding: SS and SLK. 
Funding This project was supported by the Blue Cross Blue Shield of Michigan Foundation grant 2413.II and the US Department of Veterans Affairs (VA), including a VA National Center for Patient Safety funded Patient Safety Center of Inquiry. Dr Krein was also supported by a VA Health Services Research and Development Service Research Career Scientist award (RCS 11-222).

Disclaimer The study sponsors had no role in the design or conduct of the study; the collection, management, analysis and interpretation of the data; of the preparation, review or approval of the manuscript.

Competing interests SS reports receiving honoraria for lectures and teaching related to the prevention of hospital-acquired infection and serving on the medical advisory boards for Doximity (a social networking site for physicians) and Jvion (a health care technology company). JM reports receiving honoraria for lectures and teaching related to prevention and value-based policies involving catheter-associated urinary tract infection and hospital-acquired pressure ulcers. SS and JM hold a provisional US patent on a technology to improve aseptic placement of urinary catheters, which was not part of this study.

Patient consent for publication Not required.

Provenance and peer review Not commissioned; internally peer reviewed.

Open access This is an open access article distributed in accordance with the Creative Commons Attribution Non Commercial (CC BY-NC 4.0) license, which permits others to distribute, remix, adapt, build upon this work noncommercially, and license their derivative works on different terms, provided the original work is properly cited, appropriate credit is given, any changes made indicated, and the use is noncommercial. See: http://creativecommons.org/licenses/by-nc/4. $0 /$.

\section{REFERENCES}

1 Centers for Medicare and Medicaid Services (CMS), HHS. Medicare program: Changes to the hospital inpatient prospective payment systems and fiscal year 2009 rates; payments for graduate medical education in certain emergency situations; changes to disclosure of physician ownership in hospitals and physician self-referral rules; updates to the longterm care prospective payment system; updates to certain IPPSexcluded hospitals; and collection of information regarding financial relationships between hospitals. Final rules. Fed Regist 2008;73:48433-84.

2 Office of Disease Prevention and Health Promotion. National action plan to prevent health care-associated infections: roadmap to elimination - health care-associated infections Washington, D.C.: US Department of Health and Human Services, 2018. Available: http://www.health.gov/hai/prevent_ hai.asp [Accessed 14 Aug 2018].

3 Office of Disease Prevention and Health Promotion. Health. gov health Care quality, health care-associated infections, National targets and metrics: U.S. department of health and Human services, 2018. Available: https://health.gov/hcq/ prevent-hai-measures.asp [Accessed 25 Jul 2018].

4 Jeeva RR, Wright D. Healthcare-associated infections: a national patient safety problem and the coordinated response. Med Care 2014;52(2 Suppl 1):S4-8.

5 Healthy People 2020. Healthcare-associated infections: overview Washington, dc: U.S. department of health and Human services, 2018. Available: http://www.healthypeople. gov/2020/topicsobjectives2020/overview.aspx?topicid $=17$ [Accessed 14 Aug 2018].
6 Pronovost P, Jha AK. Did Hospital engagement networks actually improve care? N Engl J Med 2014;371:691-3.

7 McKibben L, Horan T, Tokars JI, et al. Guidance on public reporting of healthcare-associated infections: recommendations of the Healthcare Infection and Control Practices Advisory Committee. Am J Infect Control 2005;33:217-26.

8 Centers for Medicare \& Medicaid Services. Hospital acquired condition reduction program (HACRP), 2018. Available: https://www.cms.gov/Medicare/Medicare-Fee-for-ServicePayment/AcuteInpatientPPS/HAC-Reduction-Program.html [Accessed 14 Aug 2018].

9 Centers for Medicare \& Medicaid Services. Hospital valuebased purchasing, 2017. Available: https://www.cms.gov/ Medicare/Quality-Initiatives-Patient-Assessment-Instruments/ HospitalQualityInits/Hospital-Value-Based-Purchasing-.html [Accessed 14 Aug 2018].

10 QualityNet. Hospital value-based purchasing (HVBP), fiscal years 2018-2023 measures, 2018. Available: http://www. qualitynet.org/dcs/ContentServer? $\mathrm{c}=$ Page\&pagename $=$ QnetPublic\%2FPage\%2FQnetTier3\&cid=1228775522697 [Accessed 14 Aug 2018].

11 Saint S, Greene MT, Kowalski CP, et al. Preventing catheter-associated urinary tract infection in the United States: a national comparative study. JAMA Intern Med 2013;173:874-9.

12 Saint S, Greene MT, Krein SL, et al. A program to prevent catheter-associated urinary tract infection in acute care. $N$ Engl J Med 2016;374:2111-9.

13 Berenholtz SM, Lubomski LH, Weeks K, et al. Eliminating central line-associated bloodstream infections: a national patient safety imperative. Infect Control Hosp Epidemiol 2014;35:56-62.

14 Marsteller JA, Hsu Y-J, Weeks K. Evaluating the impact of mandatory public reporting on participation and performance in a program to reduce central lineassociated bloodstream infections: evidence from a national patient safety collaborative. Am J Infect Control 2014;42:S209-S215.

15 Lin DM, Weeks K, Bauer L, et al. Eradicating central lineassociated bloodstream infections statewide: the Hawaii experience. Am J Med Qual 2012;27:124-9.

16 DePalo VA, McNicoll L, Cornell M, et al. The Rhode Island ICU collaborative: a model for reducing central line-associated bloodstream infection and ventilator-associated pneumonia statewide. BMJ Qual Saf 2010;19:555-61.

17 Rawat N, Yang T, Ali KJ, et al. Two-state collaborative study of a multifaceted intervention to decrease ventilator-associated events. Crit Care Med 2017;45:1208-15.

18 Pathak R, Patel A, Enuh H, et al. The incidence of central line-associated bacteremia after the introduction of midline catheters in a ventilator unit population. Infect Dis Clin Pract 2015;23:131-4.

19 Durant DJ. Nurse-driven protocols and the prevention of catheter-associated urinary tract infections: a systematic review. Am J Infect Control 2017;45:1331-41.

20 Patel PK, Gupta A, Vaughn VM, et al. Review of strategies to reduce central line-associated bloodstream infection (CLABSI) and catheter-associated urinary tract infection (CAUTI) in adult ICUs. J Hosp Med 2018;13:105-16.

21 Krein SL, Fowler KE, Ratz D, et al. Preventing deviceassociated infections in US hospitals: national surveys from 2005 to 2013. BMJ Qual Saf 2015;24:385-92. 
22 Saint S, Kowalski CP, Kaufman SR, et al. Preventing hospitalacquired urinary tract infection in the United States: a national study. Clin Infect Dis 2008;46:243-50.

23 Dillman DA. Mail and Internet surveys: the tailored design method. New York: John Wiley \& Sons, 2000.

24 Gould CV, Umscheid CA, Agarwal RK, et al. Guideline for prevention of catheter-associated urinary tract infections 2009 Infect Control Hosp Epidemiol 2010;31:319-26.

25 O'Grady NP, Alexander M, Burns LA, et al. Summary of recommendations: guidelines for the prevention of intravascular catheter-related infections. Clin Infect Dis 2011;52:1087-99.

26 Lo E, Nicolle LE, Coffin SE, et al. Strategies to prevent catheter-associated urinary tract infections in acute care hospitals: 2014 update. Infect Control Hosp Epidemiol 2014;35:464-79.

27 Marschall J, Mermel LA, Fakih M, et al. Strategies to prevent central line-associated bloodstream infections in acute care hospitals: 2014 update. Infect Control Hosp Epidemiol 2014;35:753-71.

28 Klompas M, Branson R, Eichenwald EC, et al. Strategies to prevent ventilator-associated pneumonia in acute care hospitals: 2014 update. Infect Control Hosp Epidemiol 2014;35:915-36.

29 Krein SL, Hofer TP, Kowalski CP, et al. Use of central venous catheter-related bloodstream infection prevention practices by US hospitals. Mayo Clin Proc 2007;82:672-8.

30 Pronovost P. Interventions to decrease catheter-related bloodstream infections in the ICU: the keystone intensive care unit project. Am J Infect Control 2008;36:S171.e1-S171.e5.

31 Hua F, Xie H, Worthington HV, et al. Oral hygiene care for critically ill patients to prevent ventilator-associated pneumonia. Cochrane Database Syst Rev 2016;30.

32 Saint S, Kowalski CP, Banaszak-Holl J, et al. How active resisters and organizational constipators affect health careacquired infection prevention efforts. Jt Comm J Qual Patient Saf 2009;35:239-46.

33 Harrod M, Kowalski CP, Saint S, et al. Variations in risk perceptions: a qualitative study of why unnecessary urinary catheter use continues to be problematic. BMC Health Serv Res 2013;13.

34 Krein SL, Kowalski CP, Harrod M, et al. Barriers to reducing urinary catheter use: a qualitative assessment of a statewide initiative. JAMA Intern Med 2013;173:881-6. 